\title{
Mechanical Properties of 3C-SiC Films for MEMS Applications
}

Jayadeep Deva Reddy ${ }^{1}$, Alex A. Volinsky ${ }^{1}$, Christopher L. Frewin ${ }^{2}$, Chris Locke ${ }^{2}$, and Stephen E. Saddow ${ }^{2}$

${ }^{1}$ Department of Mechanical Engineering, University of South Florida, 4202 E. Fowler Ave. ENB118, Tampa, FL, 33620

${ }^{2}$ Department of Electrical Engineering, University of South Florida, 4202 E. Fowler Ave. ENB118, Tampa, FL, 33620

\section{ABSTRACT}

There is a technological need for hard thin films with high elastic modulus and fracture toughness. Silicon carbide (SiC) fulfills such requirements for a variety of applications at high temperatures and for high-wear MEMS. A detailed study of the mechanical properties of single crystal and polycrystalline 3C-SiC films grown on $\mathrm{Si}$ substrates was performed by means of nanoindentation using a Berkovich diamond tip. The thickness of both the single and polycrystalline $\mathrm{SiC}$ films was around 1-2 $\mu \mathrm{m}$. Under indentation loads below $500 \mu \mathrm{N}$ both films exhibit Hertzian elastic contact without plastic deformation. The polycrystalline SiC films have an elastic modulus of $457 \pm 50 \mathrm{GPa}$ and hardness of $33.5 \pm 3.3 \mathrm{GPa}$, while the single crystalline $\mathrm{SiC}$ films elastic modulus and hardness were measured to be $433 \pm 50 \mathrm{GPa}$ and $31.2 \pm 3.7 \mathrm{GPa}$, respectively. These results indicate that polycrystalline $\mathrm{SiC}$ thin films are more attractive for MEMS applications when compared with the single crystal 3C-SiC, which is promising since growing single crystal $3 \mathrm{C}-\mathrm{SiC}$ films is more challenging.

\section{INTRODUCTION}

The development of $\mathrm{SiC}$ as a microelectronic material for over 2 decades has resulted in enormous prospects for its use in MEMS applications [1, 2]. Mechanical properties of thin films play a pivotal role in determining the lifetime of MEMS devices. We studied cubic $\mathrm{SiC}$ (3C-SiC) films grown on Si substrates, which are chemically inert, can withstand high temperatures, and have a high resistance to oxidation. Silicon carbide also has excellent electronic and thermal properties, including large reverse breakdown voltage, high electron mobility, high saturated electron drift velocity and excellent thermal conductivity relative to $\mathrm{Si}$ [3], making $\mathrm{SiC}$ attractive for MEMS applications under hostile conditions. Present trends indicate an increasing interest in the cubic polycrystalline form of $\mathrm{SiC}$, namely poly-3C-SiC, as a MEMS material since it can be deposited on various substrates and micromachined in a similar fashion to $\mathrm{Si}$ [4].

Silicon carbide exists in more than 200 polytypes, but only a few are useful in fabricating semiconductor devices, of which $3 \mathrm{C}-\mathrm{SiC}$ has been widely developed for semiconductors. Since silicon carbide can exist in both polycrystalline and single crystal forms, it is important to compare which film is best suited for MEMS applications by measuring their relative mechanical properties. There are various methods used in determining the mechanical properties of thin films, including the bulge test, micro-beam bending, the micro tensile test [2], nanoindentation, etc. In this paper nanoindentation was used to characterize the mechanical properties of single crystal and polycrystalline 3C-SiC films grown on Si substrates in order to shed light on which is better suited for MEMS applications, which require good mechanical properties such as hardness, elastic modulus and fracture toughness. 


\section{EXPERIMENT}

Single crystal (3C-SiC) and polycrystalline (poly-3C-SiC) $\mathrm{SiC}$ samples were grown on $\mathrm{Si}$ (100) substrates. The samples were grown heteroepitaxially via chemical vapor deposition (CVD) in a hot-wall reactor [3]. The thickness of the samples was around 1-2 $\mu \mathrm{m}$. The crystallographic orientations of the samples were not taken into consideration for the mechanical properties measurements since one of the films was polycrystalline. The orientation of the single crystal SiC film was (100).

\section{Growth of single crystal 3C-SiC films}

3C-SiC single crystal films were grown on a $50 \mathrm{~mm}$ diameter $\mathrm{Si}$ (100) wafer using a hotwall CVD process. Details of both the reactor and the growth process can be found elsewhere [5]. The 3C-SiC on $\mathrm{Si}$ deposition process was developed using the two step carbonization and growth method. $\mathrm{C}_{3} \mathrm{H}_{8}$ and $\mathrm{SiH}_{4}$ were used as the precursor gases to provide carbon and silicon, respectively. Ultra-high purity hydrogen, purified in a palladium diffusion cell, was employed as the carrier gas. Prior to growth, the Si substrates were prepared using the standard RCA cleaning method [6], followed by a 30 second immersion in diluted hydrofluoric acid to remove surface contaminants and the surface oxide. The first stage of the process, known as the carbonization step, involved heating the $\mathrm{Si}$ substrate from room temperature to $1140{ }^{\circ} \mathrm{C}$ at atmospheric pressure with a gas flow of 6 standard cubic centimeters per minute $(\mathrm{sccm})$ of $\mathrm{C}_{3} \mathrm{H}_{8}$ and 10 standard liters per minute (slm) of $\mathrm{H}_{2}$. The temperature was then maintained for two minutes to carbonize the substrate surface. After carbonization, $\mathrm{SiH}_{4}$ was introduced into the system at 4 sccm and the temperature was increased to the growth temperature of $1375^{\circ} \mathrm{C}$, and the pressure was changed to 100 Torr for approximately 5 minutes. The temperature and gas flow rates were then maintained at these values during the growth process. By this procedure, a $2 \mu \mathrm{m}$ thick $3 \mathrm{C}$ $\mathrm{SiC}$ film was grown [7]. After the growth process was completed, the wafer was cooled to room temperature in an Ar atmosphere [3]. After deposition the film thickness was measured by Fourier transform infrared reflectance spectroscopy (FTIR) and confirmed by cross-section scanning electron microscopy analysis. The crystal orientation of the grown film was determined by X-ray diffraction (XRD) using a Philips X-Pert X-ray diffractometer. XRD data showed that the films were single crystal with an X-ray rocking curve FWHM of approximately 300 arcsec. Figure 1 shows the rocking curve for the single crystal $3 \mathrm{C}-\mathrm{SiC}$ film.

\section{Growth of polycrystalline 3C-SiC films}

Polycrystalline growth follows the same procedure as single crystal growth with the exception of a higher flux of the growth species. The process conditions for the samples studied here were therefore identical to those listed above except that the $\mathrm{SiH}_{4}$ and $\mathrm{C}_{3} \mathrm{H}_{8}$ mass flow rates were 300 and $8.5 \mathrm{sccm}$, respectively. This process resulted in a poly-3C-SiC film with a thickness of approximately $4 \mu \mathrm{m}$. 


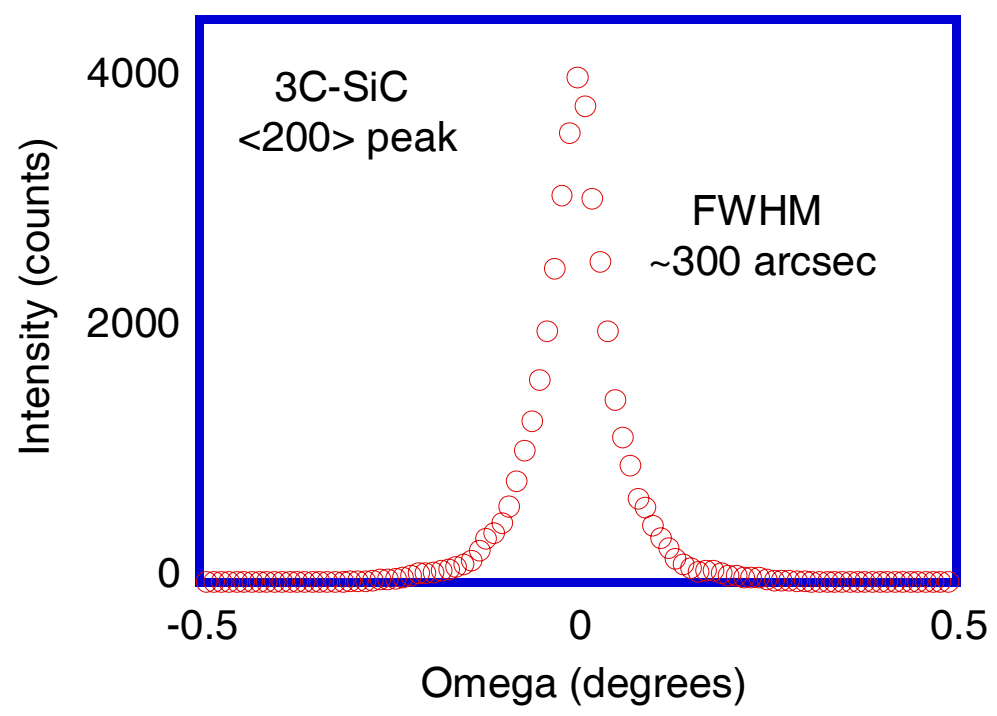

Figure 1. Rocking curve from the (200) plane for the 3C-SiC film grown on (100) Si, confirming that the film is single crystal $3 \mathrm{C}-\mathrm{SiC}$.

\section{$\underline{\text { Nanoindentation procedure }}$}

Nanoindentation experiments were performed using a Hysitron Triboindenter. A Berkovich indenter was used to perform all indentation tests. Load controlled indentations were done to determine the elastic modulus and hardness of the films. The indenter tip was calibrated using a quartz standard to determine the tip area function [8]. The radius of the Berkovich tip was approximately $100 \mathrm{~nm}$, which was also confirmed by using the Hertzian theory of elastic contact $[9,10]$.

The single crystal 3C-SiC sample had an optically smooth (mirror) surface requiring no polishing prior to nanoindentation. However, the polycrystalline sample had a rough morphology which required mechanical polishing. Polycrystalline 3C-SiC films of the same approximate thickness were prepared on $\mathrm{Si}$ substrates from the same wafer lot to conduct indentation experiments. The sample was polished on a polishing pad using $1 \mu \mathrm{m}$ diamond paste to both thin down the thickness of the film to match the single crystal film thickness and to smooth out the film surface roughness; the resulting film thickness was equivalent to the single crystal $\mathrm{SiC}$ film $(1-2 \mu \mathrm{m})$. Samples were then cleaved and glued to the sample holders using Super glue and placed on the indenter stage for measurement. Each indent was performed individually after scanning the sample surface to ensure its local smoothness.

The low load transducer, which can apply a maximum load of $10 \mathrm{mN}$, was used to determine the elastic modulus $(\mathrm{E})$ and hardness $(\mathrm{H})$ of the $3 \mathrm{C}-\mathrm{SiC}$ films. The experiment was carried out at loads varying from 0.5 to $10 \mathrm{mN}$ on both the single crystal and polycrystalline $\mathrm{SiC}$ samples. To determine the fracture toughness $(\mathrm{K})$, the low load transducer was replaced with a high load transducer. The above mentioned indentation procedure was followed at higher loads ranging from 100 to $1500 \mathrm{mN}$.

Small cracks on the surface of the thin films were induced when higher loads were applied. These patterns of cracks were used to estimate the fracture toughness of the films. Cracks come in different morphologies depending on the indentation load, tip indenter geometry and the material properties. The most common types of cracks observed are typically radial 
cracks for brittle and hard materials [11, 12]. Figure 4 shows the load induced radial cracks propagating from the indentation point using the Berkovich tip. Fracture toughness is calculated by using equation (1),

$$
K_{C}=A \sqrt{\frac{E}{H}} \frac{P_{\max }}{C^{1.5}}
$$

where $K_{C}$ is the fracture toughness, $P_{\max }$ is the maximum load, $C$ is the crack length, $E$ is the elastic modulus and $H$ is the hardness. $A$ is the empirical constant determined from conducting indentation into material with known fracture toughness. It is 0.039 for the cube corner indenter and 0.022 for the Vickers indenter [13]. Having similar face angle, Berkovich tip would have values similar to the Vickers indenter. Equation 1 was originally derived for bulk materials, as it assumes a half-penny shaped crack, and it does not account for the elastic moduli mismatch between the film and the substrate materials. It is not applicable for thin films on hard substrates, where the cannel crack is constrained and does not kink into the substrate. In case of the SiC film on the Si substrate the situation is different, where surface crack in $\mathrm{SiC}$ is likely to kink into the Si substrate, thus being half-penny shaped.

Wear tests on the single crystal 3C-SiC film were also performed in a 3 x $3 \mu \mathrm{m}$ area using the low load transducer at $2 \mu \mathrm{N}$ normal load and $1 \mathrm{~Hz}$ frequency. The objective of this procedure was to determine the wear resistance of the sample by repeated scanning of the poly$3 \mathrm{C}$-SiC surface. After a certain number of wear cycles the scans area was zoomed out to $5 \mathrm{x} 5$ $\mu \mathrm{m}$ to determine the material wear.

\section{DISCUSSION}

Load-controlled indentations were performed to varying maximum load, ranging from 0.5 to $10 \mathrm{mN}$. The load-displacement curves exhibited by each type of 3C-SiC material are compared in Figure 2 (a) and (b). The hardest material had less penetration depth of the tip into the sample surface and hence the graph shows less displacement for the same amount of load applied.

From Figure 2 it can be inferred that at lower load $(<500 \mu \mathrm{N})$ both the single and polycrystalline samples made elastic contact with the diamond probe. Low load curves help in determining the radius of the indenter tip used in performing the nanoindentation experiments, by using the Hertz theory of elastic contact $[9,10]$. At higher loads varying from 5 to $10 \mathrm{mN}$ plastic deformation was observed in the film. Figure 2 (b) shows the indentation done at a load of $10 \mathrm{mN}$, from which it can be inferred that the indenter penetrated more into the single crystal 3C$\mathrm{SiC}$ film surface compared to that of the polycrystalline 3C-SiC film.

Figure 3 shows the modulus and hardness values of respective $3 \mathrm{C}-\mathrm{SiC}$ films. Thin film elastic modulus ( $E_{\text {sample }}$ ) obtained by nanoindentation is calculated from:

$$
\frac{1}{E_{r}}=\frac{1-v_{\text {sample }}^{2}}{E_{\text {sample }}}+\frac{1-v_{t i p}^{2}}{E_{t i p}}
$$


where $E_{\text {tip }}=1140 \mathrm{GPa}$ and $v_{\text {tip }}=0.2$ are the elastic modulus and Poisson's ratio for the diamond tip, respectively.
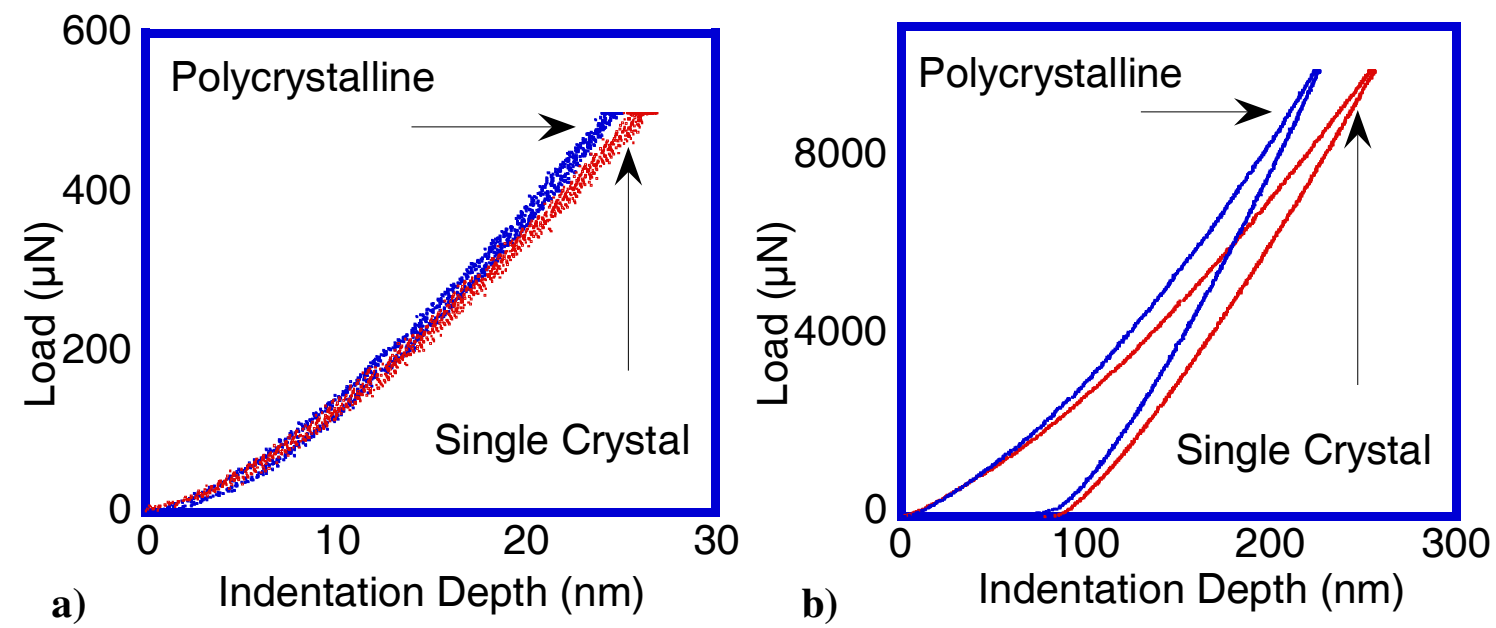

Figure 2. Load-displacement curves at the maximum load of a) $1 \mathrm{mN}$ and b) $10 \mathrm{mN}$ for polycrystalline and single crystal 3C-SiC films grown on (100) $\mathrm{Si}$.
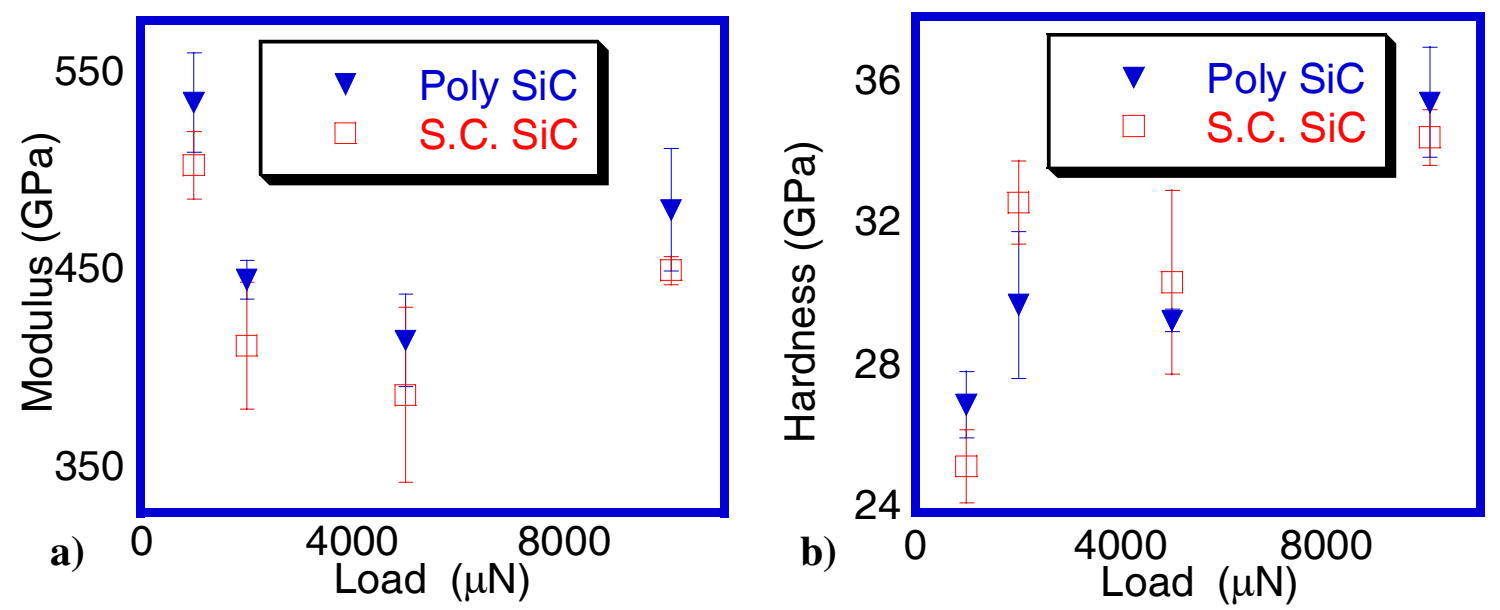

Figure 3. a) Elastic modulus and b) Hardness of single crystal and poly crystalline 3C-SiC films grown on (100) Si. Corresponding maximum indentation depths are 60, 80, 160 and $250 \mathrm{~nm}$, respectively.

Table I reports the average values of the measured hardness and the elastic modulus of single crystal 3C-SiC, polycrystalline 3C-SiC, a 15R-SiC Lely platelet and Si (100) substrate. At least five indents were performed at each maximum load. 15R-SiC was used as a comparison since this material is known to have a minimum amount of dislocations. There is a relatively large absolute variation in measured elastic modulus ( $\pm 50 \mathrm{GPa})$, not typically observed in indentation of softer materials. One has to consider the relative variation, which is typically on the order of $10 \%$. The reported mechanical properties are for a maximum indentation depth range between 60 and $250 \mathrm{~nm}$, where quartz calibration is reasonable. 
Table I. Measured SiC mechanical properties.

\begin{tabular}{|c|c|c|}
\hline Material & Hardness (GPa) & Elastic Modulus (GPa) \\
\hline Silicon (100) & $12.46 \pm 0.78$ & $172.13 \pm 7.76$ \\
\hline Lely platelet 15R-SiC & $42.76 \pm 1.19$ & $442 \pm 16.34$ \\
\hline Single crystal 3C-SiC on (100) Si & $31.198 \pm 3.7$ & $433 \pm 50$ \\
\hline Polycrystalline 3C-SiC on (100) Si & $33.54 \pm 3.3$ & $457 \pm 50$ \\
\hline
\end{tabular}

Figure 4 shows the microscopic images of cracks induced at higher loads in polycrystalline and single crystal 3C-SiC, respectively. The crack lengths were used to calculate the film fracture toughness using equation (1). Radial cracks were generated along the sharp corners of the Berkovich tip. Table II gives fracture toughness values of respective SiC films on the $\mathrm{Si}$ substrate along with the bulk $\mathrm{SiC}$ fracture toughness measured by conventional techniques and nanoindentation [14]. Normally nanoindentation fracture toughness method employing equation 1 gives $40 \%$ variability compared with other techniques. The cause for the low fracture toughness in our case compared to the bulk values is due to the tip penetrating into the $\mathrm{Si}$ substrate and substrate fracture skewing the results to a lower substrate fracture toughness value. Note that for the single crystal $3 \mathrm{C}-\mathrm{SiC}$ film radial cracks are aligned along the Si substrate crystallographic orientation (Figure 4 b) opposite to typical radial cracks in the poly-3C-SiC in Figure 4a.

Table II. SiC fracture toughness.

\begin{tabular}{|c|c|}
\hline Material & Fracture Toughness $\left(\mathrm{MPa} \cdot \mathrm{m}^{1 / 2}\right)$ \\
\hline Single crystal 3C-SiC film on $\mathrm{Si}$ & $1.59 \pm 0.21$ \\
\hline Polycrystalline 3C-SiC film on Si & $1.54 \pm 0.28$ \\
\hline Bulk SiC & 4.6 \\
\hline Bulk SiC (Eq. 1) [14] & $3.1 \pm 0.9$ \\
\hline
\end{tabular}
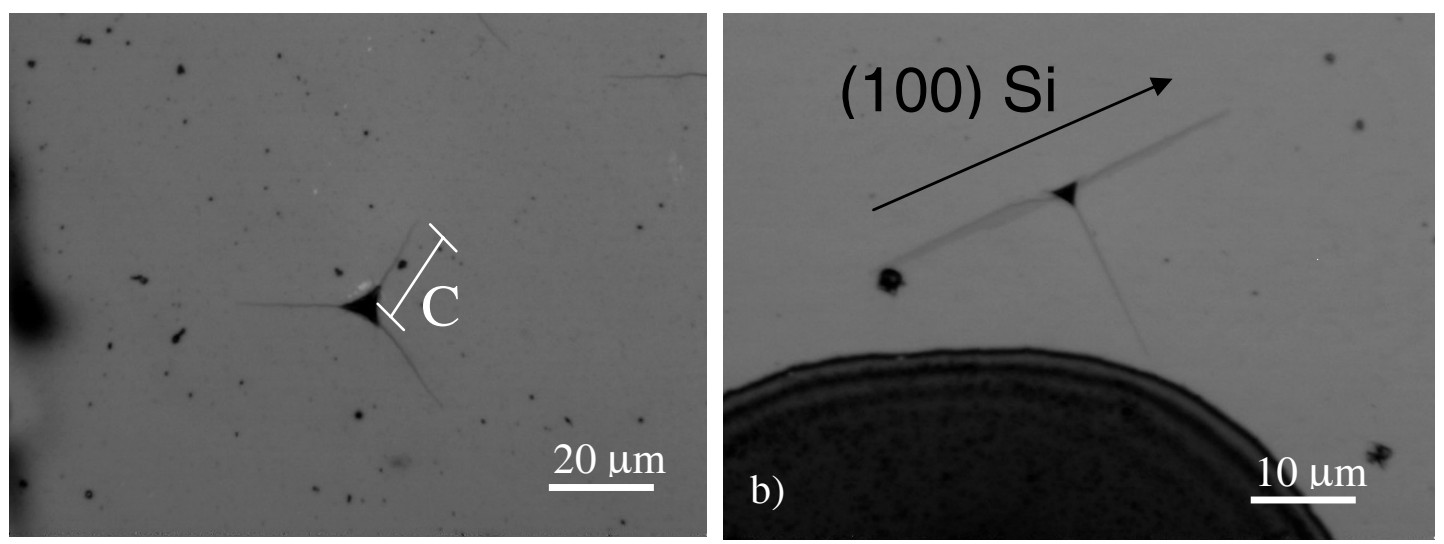

Figure 4. Micrographs of a) Poly-3C-SiC film on (100) Si substrate indent at $1500 \mathrm{mN}$ and b) $3 \mathrm{C}-\mathrm{SiC}$ film on (100) $\mathrm{Si}$ substrate indent at $1000 \mathrm{mN}$. 
Since it was determined that poly-3C-SiC film has higher hardness and elastic modulus, thus is better suited for MEMS applications, it was also tested for wear resistance. Figure 5 shows the topography images and corresponding line profiles of the polycrystalline $3 \mathrm{C}-\mathrm{SiC}$ surface before and after tip-induced wear test performed for 1045 scans. During scanning there was very little or negligible wear, as only 1-2 nm of material depth was removed. This result confirms the high wear resistance of poly-3C-SiC films necessary for MEMS applications.
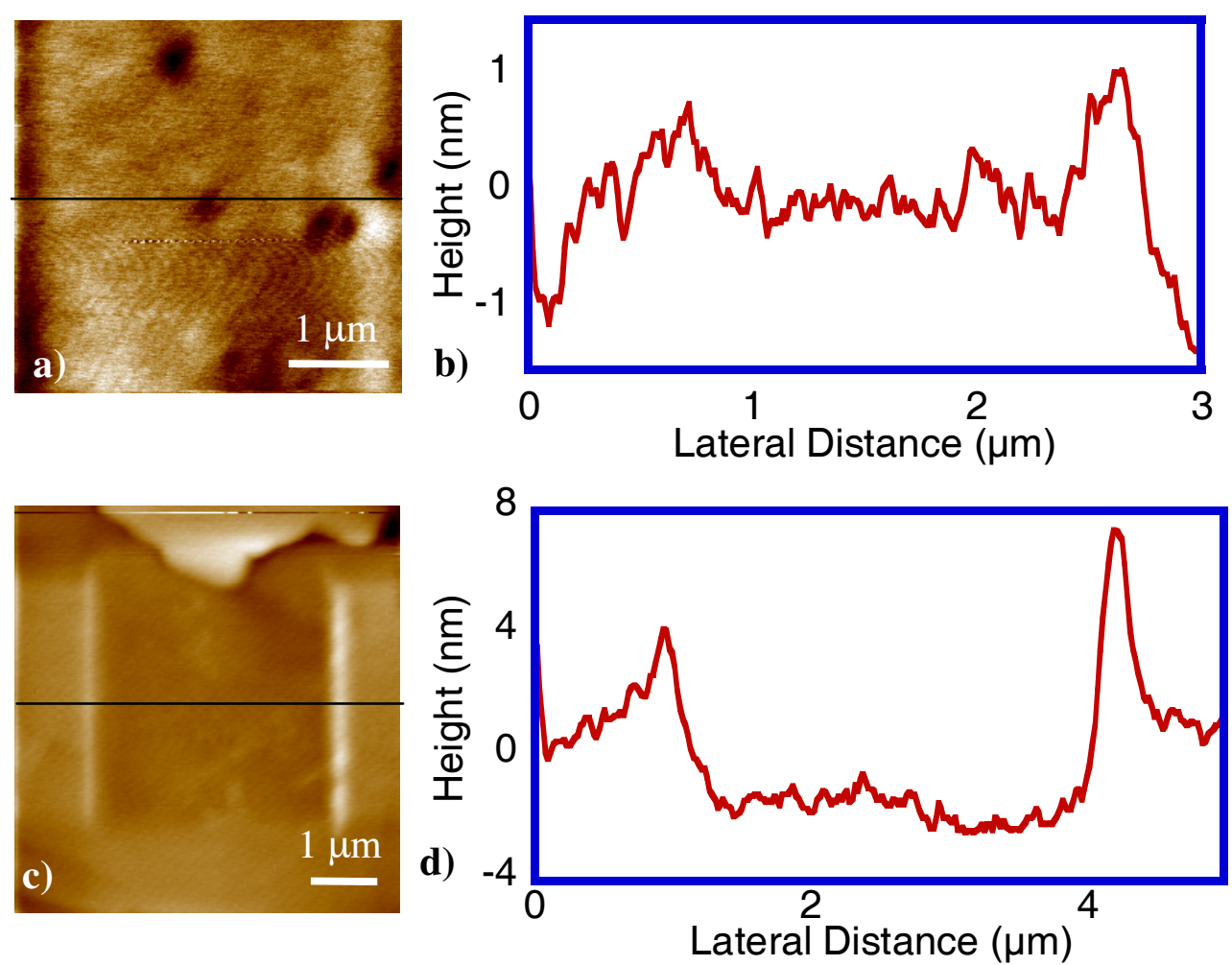

Figure 5. a) Topography image of the original poly-3C-SiC surface and b) Line scan showing initial surface roughness; c) Wear square area after 1045 scans and d) Corresponding line profile showing about $2 \mathrm{~nm}$ of wear depth.

\section{CONCLUSIONS}

3C-SiC thin films grown on (100) Si for MEMS applications were observed to be very hard and have high elastic modulus compared to the silicon wafers. The nanoindentation results show that polycrystalline $\mathrm{SiC}$ films have better mechanical properties compared to single crystal 3C-SiC films and should be suitable for MEMS applications in harsh environments.

\section{ACKNOWLEDGEMENTS}

The 3C-SiC growth in S.E. Saddow's laboratory was supported by the Army Research Laboratory under Grant No. DAAD19-R-0017 (B. Geil) and the Office of Naval Research under 
Grant No. W911NF-05-2-0028 (C. E. C. Wood). Alex Volinsky would like to acknowledge support from NSF under CMMI contracts 0631526, 0600266 and 0600231.

\section{REFERENCES}

1. M. Ohring, The Material Science of Thin Films, Academic Press, San Diego, (1992).

2. K.M. Jackson, J. Dunning, C.A. Zorman, M. Meheregany, W.N. Sharpe, Journal of Microelectromechanical Systems, Vol. 14, No. 4, August (2005).

3. R.F. Davis, G. Kelner, M. Shur, J.W. Palmour and J. Edmond, Proc. IEEE 79 (1991) 677.

4. C.A. Zorman, S. Roy, C.H.Wu, A.J. Flieschman, M. Mehregany, J. Mater. Res.13 (1998) 406.

5. R. L. Myers, Y. Shishkin, O. Kordina, and S.E. Saddow, Journal of Crystal Growth vol. 285/4, (2005) 483-486.

6. W. Kern and D. A. Puotinen, RCA Rev. Vol. 31, (1970) 187-206.

7. M. Reyes, Y. Shishkin, S. Harvey, S.E. Saddow, Mat. Res. Soc. Symp. Proc. Vol. 911, (2006) 79.

8. W.C. Oliver, G.M. Pharr, J. Mater. Res. 7 (1992) 1562.

9. K.L. Johnson, Contact Mechanics, Cambridge University Press, (1985).

10. S.P. Timoshenko and J.N. Goodier, Theory of Elasticity, McGraw-Hill, New York, (1970).

11. G.R. Anstis, P. Chantikul, B.R. Lawn, D.B. Marshall. J. Am. Ceram. Soc (1981). 64:533.

12. D. Casellas, J. Caro, S. Molas, J. M. Prado, I. Valls, Acta Mater. 55 (2007) 4277-4286.

13. R.F. Cook, Ph. D. Thesis, University of New South Wales, Sydney, New South Wales, Australia, 1986.

14. D. Yang and T. Anderson, Fracture Toughness of SiC Determined by Nanoindentation, Application Note, Hysitron Inc. World Wide Web: http://www.hysitron.com/page_attachments/0000/0367/111500-001.pdf 